\title{
Age-Related Macular Degeneration: Insights into Inflammatory Genes
}

\author{
Raffaella Cascella, ${ }^{1}$ Michele Ragazzo, ${ }^{1}$ Claudia Strafella, ${ }^{1}$ Filippo Missiroli,, \\ Paola Borgiani, ${ }^{1}$ Francesco Angelucci, ${ }^{3}$ Luigi Tonino Marsella, ${ }^{1}$ Andrea Cusumano, ${ }^{2}$ \\ Giuseppe Novelli, ${ }^{1}$ Federico Ricci, ${ }^{2}$ and Emiliano Giardina ${ }^{1,3}$ \\ ${ }^{1}$ Department of Biomedicine and Prevention, School of Medicine, University of Rome "Tor Vergata", \\ Via Montpellier 1, 00133 Rome, Italy \\ ${ }^{2}$ UOSD Retinal Pathology PTV Foundation "Policlinico Tor Vergata", Viale Oxford 81, 00133 Rome, Italy \\ ${ }^{3}$ Molecular Genetics Laboratory UILDM, Santa Lucia Foundation, Via Ardeatina 354, 00142 Rome, Italy \\ Correspondence should be addressed to Raffaella Cascella; raffaellacascella@virgilio.it
}

Received 31 July 2014; Revised 23 October 2014; Accepted 23 October 2014; Published 12 November 2014

Academic Editor: Haoyu Chen

Copyright (C) 2014 Raffaella Cascella et al. This is an open access article distributed under the Creative Commons Attribution License, which permits unrestricted use, distribution, and reproduction in any medium, provided the original work is properly cited.

Age-related macular degeneration (AMD) is a progressive neurodegenerative disease that affects approximately $8.7 \%$ of elderly people worldwide ( $>55$ years old). AMD is characterized by a multifactorial aetiology that involves several genetic and environmental risk factors (genes, ageing, smoking, family history, dietary habits, oxidative stress, and hypertension). In particular, ageing and cigarette smoking (including oxidative compounds and reactive oxygen species) have been shown to significantly increase susceptibility to the disease. Furthermore, different genes (CFH, CFI, C2, C3, IL-6, IL-8, and ARMS2) that play a crucial role in the inflammatory pathway have been associated with AMD risk. Several genetic and molecular studies have indicated the participation of inflammatory molecules (cytokines and chemokines), immune cells (macrophages), and complement proteins in the development and progression of the disease. Taking into consideration the genetic and molecular background, this review highlights the genetic role of inflammatory genes involved in AMD pathogenesis and progression.

\section{Introduction}

Age-related macular degeneration (AMD, OMIM \#610149) is a progressive neurodegenerative and multifactorial disease that impairs the visual field $[1,2]$. Its clinical symptoms include a gradual loss of central vision, the distortion of images and straight lines, and the presence of blurry and dark areas in the central vision. Consequently AMD substantially impacts the lifestyle of patients by compromising everyday activities, such as reading and driving [3-5].

AMD affects approximately $8.7 \%$ of the elderly population worldwide ( $>55$ years old), especially in developed countries. The number of AMD cases is expected to increase to 196 million in 2020 and to 288 million in 2040 [6]. To date, more than 1 and 10 million people suffer from this ocular disease in Italy and the USA, respectively $[7,8]$.
The disease affects the small central portion of the retina, known as the macula lutea, which is essential for the visualization of fine details and image resolution. In the macula lutea, the most common hallmarks of this disease can be recognized in the form of drusen (aggregates of extracellular material) and the growth of choroidal vessels (choroidal neovascularization) $[9,10]$. Excess of drusen and neovascularization results in chronic changes of the macula and in particular of the retinal pigment epithelium (RPE), choriocapillaries (CC), photoreceptors (rods and cones), and Bruch's membrane (BrM) [11-14]. Two forms of AMD can be distinguished based on anatomic abnormalities: atrophic (dry or nonexudative form) and neovascular or exudative (wet form) [15]. The first, which is known as geographic atrophy, is characterized by the progressive accumulation of drusen between the RPE and CC. Excessive drusen between the RPE and CC hampers 
the transport of oxygen and nutrients, which degenerates the RPE and photoreceptor system. The dry form may also progress to the more aggressive wet form of AMD, which is characterized by choroidal neovascularization. The process of angiogenesis leads to the formation of very fragile blood vessels, which are responsible for bleeding and the disruption of RPE cells [16, 17].

AMD is a multifactorial disease that involves a continuous interaction between genetic and environmental factors [18]. Among environmental factors, ageing and cigarette smoking significantly contribute to an increase in the AMD risk $[19,20]$. In particular, the disease prevalence increased with age and the loss of rod photoreceptors (approximately $30 \%$ ), which is the result of ageing and thus acts as a joint cause of AMD development [21].

Several studies demonstrated that the AMD risk odds ratio (OR) varies from 1 (in 55-69-year-old people) to 4.428.70 (in 70-79-year-old people) and up to 18.8-32.3 (in 8086-year-old people) [6]. Cigarette smoke contains a high number of toxic substances, which contribute to atherosclerosis, endothelial dysregulation, and angiogenesis. The presence of oxidative compounds in cigarettes is associated with increased reactive oxygen species formation (ROS) and thereby with oxidative damage at the RPE cell level [22-26]. In addition, dietary habits may contribute to disease progression [27]. In fact, dietary supplementation with vitamins $C$, E, B6, and B12, lutein, zeaxanthin, and zinc has been shown to slow the progression of macular degeneration toward more severe atrophic and/or neovascular forms [28-34].

Concerning the genetic picture of AMD, concordance studies of twins described hereditability as one of the main genetic risk factors for the disease. In fact, the familiarity was estimated to be at least $11 \%$ in the presence of one affected first-relative; however, the AMD risk was proven to increase 2.4-fold compared to families without the disease [35-39]. Moreover, a number of studies performed between 2005 and 2007 highlighted $A R M S 2$ and $C F H$ as the major susceptibility loci of the disease, which can cover $50-60 \%$ of the AMD genetic picture [40-47]. Genome-wide association studies (GWAS) successively identified common risk variants localized in 17 candidate genes (Table 1) that are potentially involved in the development and progression of the disease [48].

The genes associated with AMD play different roles, but the majority have been demonstrated to serve a function in the inflammatory pathway (Table 2). The knowledge of this association suggested the involvement of inflammatory components in the aetiopathogenesis of the disease. In this context, molecular studies reported the presence of several immunologic and inflammatory molecules in drusen that play a pivotal role in disease progression [49-52].

The aim of this review is to underline the genetic role of inflammatory genes associated with AMD pathogenesis.

\section{The Role of Inflammation in AMD Pathogenesis}

Inflammation is the first biological response to infection with pathogens (bacteria, virus, and fungus) or irritant
TABLE 1: Candidate genes involved in AMD pathogenesis, following GWAS.

\begin{tabular}{lcc}
\hline Gene & Locus & SNP \\
\hline C2-CFB & $6 \mathrm{p} 21.33$ & $\mathrm{rs} 429608 \mathrm{~A} / \mathrm{G}$ \\
C3 & $19 \mathrm{p} 13.3$ & $\mathrm{rs} 2230199 \mathrm{C} / \mathrm{G}$ \\
TIMP3 & $22 \mathrm{q} 12.3$ & $\mathrm{rs} 5749482 \mathrm{C} / \mathrm{G}$ \\
APOE & $19 \mathrm{q} 13.2$ & $\mathrm{rs} 4420638 \mathrm{G} / \mathrm{A}$ \\
CETP & $16 \mathrm{q} 21$ & $\mathrm{rs} 1864163 \mathrm{G} / \mathrm{A}$ \\
VEGFA & $6 \mathrm{p} 21.1$ & $\mathrm{rs} 943080 \mathrm{C} / \mathrm{T}$ \\
TNFRSF10A & $8 \mathrm{p} 21.3$ & $\mathrm{rs} 13278062 \mathrm{G} / \mathrm{T}$ \\
LIPC & $15 \mathrm{q} 21$ & $\mathrm{rs} 920915 \mathrm{C} / \mathrm{G}$ \\
CFI & $4 \mathrm{q} 25$ & $\mathrm{rs} 4698775 \mathrm{G} / \mathrm{T}$ \\
COL10A1 & $6 \mathrm{q} 21$ & $\mathrm{rs} 3812111 \mathrm{~A} / \mathrm{T}$ \\
COL8A1 & $3 \mathrm{q} 12.1$ & $\mathrm{rs} 13081855 \mathrm{G} / \mathrm{T}$ \\
IER3 & $6 \mathrm{p} 21.3$ & $\mathrm{rs} 3130783 \mathrm{~A} / \mathrm{G}$ \\
SLC16A8 & $22 \mathrm{q} 13.1$ & $\mathrm{rs} 8135665 \mathrm{C} / \mathrm{T}$ \\
TGFBR1 & $9 \mathrm{q} 22$ & $\mathrm{rs} 334353 \mathrm{~T} / \mathrm{G}$ \\
RAD51B & $14 \mathrm{q} 23$ & $\mathrm{rs} 8017304 \mathrm{~A} / \mathrm{G}$ \\
ADAMTS9 & $3 \mathrm{p} 14.1$ & $\mathrm{rs} 6795735 \mathrm{C} / \mathrm{T}$ \\
B3GALTL & $13 \mathrm{q} 12.3$ & $\mathrm{rs} 9542236 \mathrm{C} / \mathrm{T}$ \\
\hline
\end{tabular}

TABLE 2: AMD genes involved in the inflammatory pathway.

\begin{tabular}{lcc}
\hline Gene & Locus & Function \\
\hline$I L-1$ & $2 \mathrm{q} 14$ & Cytokine \\
$I L-6$ & $7 \mathrm{p} 15.3$ & Cytokine \\
IL-8 & $4 \mathrm{q} 12-\mathrm{q} 13$ & Chemokine \\
CCL3 & $17 \mathrm{q} 11.2-\mathrm{q} 12$ & Chemokine \\
CCL4 & $17 \mathrm{q} 11.2-\mathrm{q} 12$ & Chemokine \\
CCR3 & $3 \mathrm{p} 21.3$ & Chemokine receptor \\
CFH & $1 \mathrm{q} 31$ & Complement factor H \\
C2 & $6 \mathrm{p} 21.33$ & Complement component 2 \\
CFB & $6 \mathrm{p} 21.33$ & Complement factor B \\
C3 & $19 \mathrm{p} 13.3-\mathrm{p} 13.2$ & Complement component 3 \\
C9 & $5 \mathrm{p} 13.1$ & Complement component 9 \\
CFI & $4 \mathrm{q} 25$ & Complement factor 1 \\
ARMS2 & $10 \mathrm{q} 26.16$ & Possible activation of \\
NLRP3 & $1 \mathrm{q} 44$ & proinflammatory molecules \\
\hline
\end{tabular}

compounds, and this response represents a protective attempt to remove the injurious stimuli from the organism [53]. The physiological role of inflammation is to preserve tissue homeostasis and restore tissue functionality; nevertheless, this process is also known to be involved in the pathophysiology of different chronic diseases (atherosclerosis, psoriasis, arthritis, inflammatory bowel disease, and neurodegenerative diseases) [54-58].

Of the five common tissue responses that characterize inflammation (rubor, tumor, calor, dolor, and functio laesa), immunity (innate and adaptive) operates as the sixth actor in the inflammatory scenery [59]. In this context, inflammatory mediators work in tandem with immune cells to regulate 
acute and chronic inflammation and trigger tissue injury, oxidative stress, extracellular matrix remodelling, angiogenesis, and fibrosis in damaged tissues [60].

The recognition of pathogens and toxins by pattern recognition receptors (PRRs) initiates the innate immune response. The activation of PRRs is considered to be the first step of the inflammatory response [61]. PRR molecules can detect specific non-self-structures and proteins of pathogens, which are referred to as pathogen associated molecular patterns (PAMPs). Some PRRs form a multiprotein complex, known as "inflammasomes," and are involved in the maturation of proinflammatory cytokines [62-64]. The generation of a very large number of antigen receptors (T-cell receptors and immunoglobulins) able to recognize specific molecular structures of the microorganisms encountered by the host activates adaptive immunity. This specialized immunity also requires the participation of specific cytokines. Both innate and adaptive immunity induce the differentiation of effector cells (Natural-Killer cells, antibodies, and cytotoxic lymphocytes) that are responsible for the suppression of the microorganism [59].

The excessive stimulation of the inflammatory and immune responses may result in the development of several degenerative diseases, especially in tissues exposed to elevated oxidative stress and metabolic activity $[54,58,65,66]$. In this context, the macular retina represents an excellent example of such tissues. In fact, the retina is characterized by different energy-dependent mechanisms that involve high rates of oxygen consumption and mitochondrial oxidative pathways (phototransduction, neurotransmitter utilization, and protein/organelle transport) [67]. Defects in eye metabolism and oxidative stress can lead to neuronal degeneration and retinopathy. AMD is one of the most sight-threatening diseases that results in the anatomic alteration of the macula and persistent activation of inflammatory and immune mechanisms [68]. Harman suggested that AMD could be the result of disequilibrium between stress oxidative damage and repair processes, which suggests that retinal inflammatory processes may contribute to AMD pathogenesis [69]. Several associated genetic studies have implicated inflammatory molecules in the development and progression of the disease.

\section{Genes Mediating the Inflammatory Process in AMD}

3.1. Cytokines and Chemokines. Cytokines consist of soluble proteins, peptides, and glycoproteins that regulate many biological processes, including the inflammatory and immune responses. The cytokines that are produced depend on the pro- or anti-inflammatory response (IL-1, IL- 8 , and TNF- $\alpha$ or IL-4, IL-10, and IL-11, resp.). In physiological conditions, the synthesis of both types of cytokines is finely regulated and balanced. Conversely, the deregulation or abnormal production of pro- and anti-inflammatory cytokines represents several inflammatory diseases, autoimmune diseases, or immune deficiency syndromes [70, 71].

Different cytokine families can be distinguished (interleukins, interferons, and tumour necrosis factor). In particular, the interleukins (ILs) are a heterogeneous class of cytokines involved in the activation of T lymphocytes, B lymphocytes, and macrophages. To date, approximately 40 ILs have been characterized based on their structures and functions. Interestingly, genetic polymorphisms in different IL genes (such as $I L-6$ and $I L-8)$ are known to modify the transcription and production of ILs. Some of them have been associated with AMD pathogenesis, as described in the following section [7274].

The gene that encodes IL-1 is mapped on chromosome 2q14. Different signals initiate interleukin-1 (IL-1) synthesis (i.e., microbial products), and this cytokine is involved in many inflammatory processes. In fact, IL-1 often acts synergistically with TNF as a proinflammatory molecule, inducing the production of IL-6 and IL-8. IL-6 (its corresponding gene is located on locus 7p15.3) plays a role in inflammation; it mainly stimulates the synthesis of acute phase proteins (like C-reactive protein, complement proteins) in hepatocytes $[75,76]$.

IL-8 is a member of the CXC chemokine family and plays a role in the chemotaxis of neutrophils and lymphocytes to the site of inflammation. The IL-8 gene is located on chromosome 4q12-q13. IL-8 protein acts as a mediator molecule in the interaction between two cell-surface G protein-coupled receptors (CXCR1 and CXCR2), and it is also recognized as a primary mediator of angiogenesis [77, 78]. Given its functions, IL-8 plays a pivotal role in the progression of advanced cancer, including angiogenesis, tumour growth, and metastasis. Moreover, IL-8, which is an important mediator of angiogenesis, contributes to plaque formation in human coronary atherosclerosis [79-81].

Given its role in inflammatory mechanisms, $I L-8$ may represent a potential candidate gene involved in AMD progression [80]. Several studies have associated a number of $I L$ 8 polymorphisms with AMD in Asiatic and North European populations. Concerning the Italian population, Ricci et al. performed a genotyping analysis via real-time PCR (TaqMan chemistry) to demonstrate the association of rs 2227306 (C/T, intronic SNP in $I L-8$ gene) with AMD. The statistical analysis was performed on 721 cases and 660 healthy subjects and reported a significant $P$ value of $4.15 * 10^{-5}$ and an OR of $1.39(95 \% \mathrm{CI}=1.19-1.62)$ for the $\mathrm{T}$ allele. The entire $I L-8$ region was sequenced to determine the allele architecture of the gene, identifying three AMD-associated SNPs (rs2227346 $\mathrm{C} / \mathrm{T}$, rs1126647 A/T, and rs4073 A/T) and one susceptibility haplotype (A-T-T-T, $P$ value $=2.8 * 10^{-9}$, OR $=1.68,95 \% \mathrm{CI}=$ 1.43-1.97). The potential functional role of $I L-8$ in AMD and the correlation between the associated haplotype and its gene expression were further evaluated using mRNA expression analysis. However, the gene expression profile did not vary by genotype class or associated haplotype [82].

Another class of proinflammatory molecules that is potentially linked to AMD pathogenesis is the chemokines, which drive the migration of white blood cells to infected or damaged tissues in response to external stimuli. Chemokines are classified into four main subfamilies according to the amino acidic structure, namely, CXC, CC, C, and CX3C [83]. The genes that encode chemokines are generally clustered. 
In particular, two clusters that code for the main chemokine subfamilies (CXC and CC) are located on chromosome 4q1221 and chromosome 17q11.2-q12, respectively. The CC gene cluster contains 16 genes, and 4 of them are paralogous (CCL3-CCL3L and CCL4-CCL4L) [84]. The CCL3 and CCL4 genes further contain specific genomic regions, which are referred to as copy number variations (CNVs), and these regions confer an extensive genetic complexity and interindividual variability to the responsive chemokine molecules. The presence of CNVs in the chemokine-coding regions may be linked to different clinical phenotypes of disease $[85,86]$.

CC chemokine receptor-3 gene (CCR3) is located on the 3 p21.3 chromosome and codes for the homonymous receptor (CCR3). It is present on the surface of many cells and plays an important role in angiogenesis, particularly in the activation/ recruitment of eosinophils and macrophages to the site of inflammation. A genotyping study of Indian subjects identified rs3091250 in the CCR3 gene as being significantly associated with AMD and the homozygous TT genotype as a potential risk marker [85].

3.2. Genes of Complement System. The complement system consisted of 40 proteins that normally circulate as inactive precursors (proproteins) in the blood and are activated by protease cleavage. The complement system plays a key role in host defence, and three mechanisms can activate the immune response:

(1) the classical pathway, which proceeds via antibodyantigen complex activity,

(2) the alternative pathway, which identifies the host cell or microbial proteins,

(3) the lectin pathway, which recognizes polysaccharide residues on the microorganism surface $[87,88]$.

The deregulation and dysfunction of complement pathways can change the inflammatory response and are implicated in different diseases, including systemic lupus erythematosus, susceptibility to pyogenic infections, and AMD $[59,89]$. Molecular studies have identified many complement proteins in drusen, which are known to be the first clinical sign of the disease. In addition, genetic studies identified specific polymorphisms in complement genes $(\mathrm{CFH}, \mathrm{C} 3, \mathrm{C} 2$, $C F I$, and $C F B$ ) that have been associated with the risk of AMD development and progression [90,91].

In 2005, the CFH gene (chromosome 1q31) was strongly associated with a higher susceptibility to AMD development. $\mathrm{CFH}$ (complement factor $\mathrm{H}$ ) acts as an inhibitor of the adaptive immune response, interacting with the $\mathrm{C} 3$ protein and thereby impeding the activation of the complement pathway $[40,41]$. The most significant genetic association of the gene with the disease concerns the nonsynonymous SNP rs1061170 (T/C, Tyr402His). It encodes a specific CFH isoform, which modifies the $\mathrm{CFH}$ inhibitory function and induces the deregulation of the complement system. In particular, the homozygous CC genotype results in an increased activation of the complement cascade and has been associated with a higher risk for AMD development and progression [92, 93]. In fact, subjects who are $<95$ years old and carry the $\mathrm{C}$ variant have a $48 \%$ risk of developing AMD, as opposed to the $22 \%$ risk for noncarriers [94]. The rs1061170 SNP association with AMD was also evaluated in the Italian population to report a $P$ value $=1.1 * 10^{-13}$ and an $\mathrm{OR}=13.06(95 \% \mathrm{CI}=6.27-27.19)$ for the CC genotype [95]. Overall, these data suggest the rs1061170 SNP as one of the main genetic risk factors for AMD [92].

In 2013, several studies associated the variants in $C 2, C F B$, C3, C9, and CFI genes with the disease [96]. C2 (chromosome 6p21.33, rs9332739, rs547154) and CFB (chromosome $6 \mathrm{p} 21.33$, rs4151667 and rs641153) common variations cause nonsynonymous amino acid changes [97]. In particular, rs9332739 (G/C) results in a Glu318Asp amino acid change, rs641153 (G/A) generates a Glu32Arg amino acid change, and rs4151667 (T/A) induces a Leu304His amino acid change. The remaining C2 SNP (rs547154, G/T) is an intronic variation and does not produce any protein sequence changes. The $C 2$ and $C F B$ genes, which encode complement component 2 and complement factor $B$, have been associated with a higher AMD risk [98, 99].

The C3 gene (chromosome 19p13.3-p13.2) codes for C3 protein, which plays a pivotal role in the complement pathway via the interaction with $\mathrm{CFH}$. In particular, $\mathrm{C} 3$ is proteolytically cleaved into C3a and C3b. Both proteins are important mediators of inflammation, with C3b acting as an opsonin (responsible for the opsonisation of microorganisms) and C3a as an essential supervisor of cytokine and chemokine expression. Two susceptibility SNPs have been described in the C3 gene: rs147859257 (G/T, Lys155Gln) and rs2230199 (C/G, Gly102Arg) [99, 100].

The $C 9$ gene (chromosome 5p13.1) encodes the homonymous protein, which is involved in the final step of the complement system, via the formation of membrane attack complex (MAC). This complex is responsible for microorganism membrane disruption. In 2013, a rare variant of the C9 gene, rs34882957 (A/G, Pro167Ser), was found to be significantly associated with AMD progression. In the same study, a variant (rs4698775, G/T) of the CFI gene (chromosome 4q25) was correlated with AMD development. It encodes complement factor 1, which is an essential protease implicated in the regulation of the complement cascade [96].

Given these data, a number of polymorphisms mapped on different complement genes proved to be involved in AMD pathogenesis, although $\mathrm{CFH}$ remains the main risk locus.

3.3. The Implication of ARMS2 in AMD Susceptibility. The $A R M S 2$ gene (also known as LOC387715) is located on the 10q26.16 chromosome and codes for the age-related maculopathy susceptibility protein, whose function remains unknown [101-103].

Although the involvement of ARMS2 protein in AMD pathogenesis has to be yet clarified, several genetic studies described a number of alterations in the ARMS2 gene that are strongly associated with the disease. On this subject, Fritsche et al. first identified a deletion/insertion (indel) polymorphism (composed of a $443 \mathrm{bp}$ deletion followed by $54 \mathrm{bp}$ insertion, del443ins54) at the $3^{\prime}$ UTR of ARMS2 in 2008 [47]. A molecular study demonstrated that the del443ins54 
generates an unstable mRNA transcript that is subject to rapid degradation, which compromises proper protein translation [104]. The genotyping analysis of the del443ins54 polymorphism in the Italian population demonstrated a significant association with AMD susceptibility $\left(P\right.$ value $=2.5 * 10^{-16}$, $\mathrm{OR}=20.61,95 \% \mathrm{CI}=8.83-48.11$ in the presence of homozygosity for the del443ins54) [95].

Successive case/control studies and GWAS (genome-wide association studies) associated the ARMS2 single nucleotide polymorphism, rs10490924 (G/T), with the disease [48]. The SNP is responsible for the nonsynonymous amino acid change Ala69Ser, which increases the risk for developing AMD in individuals homozygous for the $\mathrm{T}$ allele by 7.6 -fold compared to heterozygotes. Interestingly, the del443ins54 polymorphism and the rs10490924 SNP have been found to be in strong linkage disequilibrium, which simplifies the simultaneous genetic and molecular characterization of the two risk variants in the 10q26.13 locus [99].

The presence of risk variants in the 10q26.13 locus has been further correlated with an elevated level of C-reactive protein (CRP) in subjects with no evidence of AMD compared to individuals carrying the wild-type genotypes [105]. The relationship observed between ARMS2 risk variants and high CRP serum levels suggests the potential involvement of gene polymorphisms in inflammation and perhaps in AMD development and progression [106].

Supporting this hypothesis, an expression study carried out on ARMS2 mRNA further described a possible relationship between the gene and some proinflammatory molecules (IL-6, IL-8, TNF- $\alpha$, C3, and C5). This relationship suggests a potential AMD pathogenesis mechanism [72, 107]. However, further studies are necessary to clarify the role of ARMS2 protein and its involvement in disease development.

3.4. Inflammasome. The NLRP3 inflammasome complex is a protein complex that consists of NLRP3 (NALP3), PYCARD, and caspase- 1 . It can be activated by microorganisms, specific non-self-pathogens, or danger-associated structural patterns (PAMPs and DAMPs), and it primarily induces potent proinflammatory molecules, such as IL-1 $\beta$ and IL-18 [108, 109]. Recent studies connected NLRP3 inflammasome activity to various complex diseases, such as Alzheimer's disease, atherosclerosis, and AMD [110, 111]. Moreover, the expression of the NLRP3 inflammasome in the RPE cells and the subsequent IL-1 $\beta$ release and activation implicate it in AMD pathogenesis [112-115]. However, while molecular studies have investigated the relationship between AMD and the inflammasome, data concerning their genetic features are lacking.

\section{Conclusions}

Age-related macular degeneration (AMD) represents one of the most sight-threatening diseases in developed countries. The prevalence of AMD is $2.1 \%$ in individuals aged $40-49$ years and increases dramatically to $35 \%$ in subjects aged $>80$ years [116]. The clinical course of the disease is highly variable and ranges from patients progressing to later AMD forms with little clinical evidence to patients whose clinical conditions may be stable for decades. Specifically, approximately $10-20 \%$ of patients with nonexudative AMD may progress to the exudative form if untreated [117].

An extensive study focused on the interplay between the genetic background and environmental factors involved in AMD aetiopathogenesis. Among the different risk factors (ageing, ethnicity, gender, hypertension, genetics, diet, and sunlight exposure), age represents one of the major contributors in the development of the disease. In fact, the common ageing processes are known to be responsible for structural and blood flow changes in the eye, thereby leading to the alteration and degeneration of the macula lutea. In particular, a progressive increase in the number of drusen results in the structural alteration of the macula and, subsequently, in the persistent induction of immune and inflammatory events. However, these age-related effects are not always responsible for AMD development and cannot be considered as the only triggering factors, which highlights the crucial role of genetics in the development and progression of the disease. In fact, $50-60 \%$ of the disease aetiology can be attributed to the genetic variations in the $C F H, A R M S 2$, and $I L-8$ genes, which encode complement factor $\mathrm{H}$, age-related maculopathy susceptibility protein 2 , and interleukin-8, respectively. Conversely, molecular evidence recently implicated the NLRP3 inflammasome as a potential inflammatory contributor in AMD pathogenesis, although genetic data on this subject are not available. The large majority of genetic studies performed to date have highlighted immunity and inflammation as the main characters that play a pivotal role in the pathogenesis of AMD.

In conclusion, several genetic and molecular studies have attempted to describe the pathogenetic pathways that are potentially involved in AMD. The age of the individual, other risk factors, and the genetic assessment of the individual are well known to likely affect the clinical development and progression of AMD. Future efforts should attempt to improve the genetic and epigenetic characterization of the inflammatory pathways in AMD in order to discover both innate and age-related predictive disease biomarkers as well as potential therapeutic targets.

\section{Conflict of Interests}

The authors declare that there is no conflict of interests regarding the publication of this paper.

\section{References}

[1] J. M. Seddon and L. Sobrin, "Epidemiology of age-related macular degeneration," in Albert \& Jakobiec's Principles and Practice of Ophthalmology, D. Albert, J. Miller, D. Azar, and B. Blodi, Eds., pp. 413-422, Saunders, Philadelphia, Pa, USA, 2007.

[2] A. Swaroop, E. Y. Chew, C. B. Rickman, and G. R. Abecasis, "Unraveling a multifactorial late-onset disease: from genetic susceptibility to disease mechanisms for age-related macular degeneration," Annual Review of Genomics and Human Genetics, vol. 10, pp. 19-43, 2009. 
[3] K. M. Ke, "The direct, indirect and intangible costs of visual impairment caused by neovascular age-related macular degeneration," European Journal of Health Economics, vol. 11, no. 6, pp. 525-531, 2010.

[4] L. S. Lim, P. Mitchell, J. M. Seddon, F. G. Holz, and T. Y. Wong, "Age-related macular degeneration," The Lancet, vol. 379, no. 9827, pp. 1728-1738, 2012.

[5] B. Gopinath, G. Liew, G. Burlutsky, and P. Mitchell, "Agerelated macular degeneration and 5-year incidence of impaired activities of daily living," Maturitas, vol. 77, no. 3, pp. 263-266, 2014.

[6] W. L. Wong, X. Su, X. Li et al., "Global prevalence of age-related macular degeneration and disease burden projection for 2020 and 2040: a systematic review and meta-analysis," The Lancet Global Health, vol. 2, no. 2, pp. e106-e116, 2014.

[7] World Health Organization, "VISION 2020: the Right to Sight, the global initiative for the elimination of avoidable blindness: magnitude and causes of visual impairment," Fact Sheet 282, 2004.

[8] C. A. Augood, J. R. Vingerling, P. T. V. M. de Jong et al., "Prevalence of age-related maculopathy in older Europeans: the European Eye Study (EUREYE)," Archives of Ophthalmology, vol. 124, no. 4, pp. 529-535, 2006.

[9] R. F. Mullins, S. R. Russell, D. H. Anderson, and G. S. Hageman, "Drusen associated with aging and age-related macular degeneration contain proteins common to extracellular deposits associated with atherosclerosis, elastosis, amyloidosis, and dense deposit disease," The FASEB Journal, vol. 14, no. 7, pp. 835-846, 2000.

[10] R. Van Leeuwen, C. C. W. Klaver, J. R. Vingerling, A. Hofman, and P. T. V. M. De Jong, "Epidemiology of age-related maculopathy: a review," European Journal of Epidemiology, vol. 18, no. 9, pp. 845-854, 2003.

[11] G. S. Hageman, P. J. Luthert, N. H. Victor Chong, L. V. Johnson, D. H. Anderson, and R. F. Mullins, "An integrated hypothesis that considers drusen as biomarkers of immunemediated processes at the RPE-Bruch's membrane interface in aging and age-related macular degeneration," Progress in Retinal and Eye Research, vol. 20, no. 6, pp. 705-732, 2001.

[12] D. H. Anderson, R. F. Mullins, G. S. Hageman, and L. V. Johnson, "A role for local inflammation in the formation of drusen in the aging eye," American Journal of Ophthalmology, vol. 134, no. 3, pp. 411-431, 2002.

[13] D. Bok, "Evidence for an inflammatory process in age-related macular degeneration gains new support," Proceedings of the National Academy of Sciences of the United States of America, vol. 102, no. 20, pp. 7053-7054, 2005.

[14] C. W. Spraul, G. E. Lang, and H. E. Grossniklaus, "Morphometric analysis of the choroid, Bruch's membrane, and retinal pigment epithelium in eyes with age-related macular degeneration," Investigative Ophthalmology and Visual Science, vol. 37, no. 13, pp. 2724-2735, 1996.

[15] W. R. Green, "Histopathology of age-related macular degeneration," Molecular vision, vol. 5, article 27, 1999.

[16] P. V. Algvere and S. Seregard, "Drusen maculopathy: a risk factor for AMD. Can we prevent visual loss?" Acta Ophthalmologica Scandinavica, vol. 81, no. 5, pp. 427-429, 2003.

[17] T. R. Friberg, R. A. Bilonick, and P. M. Brennen, "Risk factors for conversion to neovascular age-related macular degeneration based on longitudinal morphologic and visual acuity data," Ophthalmology, vol. 119, no. 7, pp. 1432-1437, 2012.
[18] W. Smith, J. Assink, R. Klein et al., "Risk factors for age-related macular degeneration: pooled findings from three continents," Ophthalmology, vol. 108, no. 4, pp. 697-704, 2001.

[19] National Eye Institute, Age-Related Macular Degeneration $(A M D)$, National Eye Institute, 2014.

[20] S. Velilla, J. J. García-Medina, A. García-Layana et al., "Smoking and age-related macular degeneration: review and update," Journal of Ophthalmology, vol. 2013, Article ID 895147, 11 pages, 2013.

[21] C. A. Curcio, C. Owsley, and G. R. Jackson, "Spare the rods, save the cones in aging and age-related maculopathy," Investigative Ophthalmology and Visual Science, vol. 41, no. 8, pp. 2015-2018, 2000.

[22] J. Fowles and E. Dybing, "Application of toxicological risk assessment principles to the chemical constituents of cigarette smoke," Tobacco Control, vol. 12, no. 4, pp. 424-430, 2003.

[23] F. Roth, A. Bindewald, and F. G. Holz, "Keypathophysiologic pathways in age-related macular disease," Graefe's Archive for Clinical and Experimental Ophthalmology, vol. 242, no. 8, pp. 710-716, 2004.

[24] N. L. Benowitz, "Cigarette smoking and cardiovascular disease: pathophysiology and implications for treatment," Progress in Cardiovascular Diseases, vol. 46, no. 1, pp. 91-111, 2003.

[25] P. J. Deisinger, T. S. Hill, and J. C. English, "Human exposure to naturally occurring hydroquinone," Journal of Toxicology and Environmental Health Part A, vol. 47, no. 1, pp. 31-46, 1996.

[26] A. P. DeCaprio, "The toxicology of hydroquinone-relevance to occupational and environmental exposure," Critical Reviews in Toxicology, vol. 29, no. 3, pp. 283-330, 1999.

[27] S. Zampatti, F. Ricci, A. Cusumano, L. T. Marsella, G. Novelli, and E. Giardina, "Review of nutrient actions on age-related macular degeneration," Nutrition Research, vol. 34, no. 2, pp. 95105, 2014.

[28] B. E. K. Klein, M. D. Knudtson, K. E. Lee et al., "Supplements and age-related eye conditions the beaver dam eye study," Ophthalmology, vol. 115, no. 7, pp. 1203-1208, 2008.

[29] J. P. SanGiovanni, E. Y. Chew, T. E. Clemons et al., "The relationship of dietary carotenoid and vitamin A, E, and C intake with age-related macular degeneration in a case-control study: AREDS report No. 22," Archives of Ophthalmology, vol. 125, no. 9, pp. 1225-1232, 2007.

[30] J. R. Evans and J. G. Lawrenson, "Antioxidant vitamin and mineral supplements for preventing age-related macular degeneration," Cochrane Database of Systematic Reviews, vol. 6, Article ID CD000253, 2012.

[31] E. W.-T. Chong, T. Y. Wong, A. J. Kreis, J. A. Simpson, and R. H. Guymer, "Dietary antioxidants and primary prevention of age related macular degeneration: systematic review and metaanalysis," British Medical Journal, vol. 335, no. 7623, pp. 755-759, 2007.

[32] A. E. Millen, R. Voland, S. A. Sondel et al., "Vitamin D status and early age-related macular degeneration in postmenopausal women," Archives of Ophthalmology, vol. 129, no. 4, pp. 481-489, 2011.

[33] W. G. Christen, R. J. Glynn, E. Y. Chew, C. M. Albert, and J. E. Manson, "Folic acid, pyridoxine, and cyanocobalamin combination treatment and age-related macular degeneration in women: the women's antioxidant and folic acid cardiovascular study," Archives of Internal Medicine, vol. 169, no. 4, pp. 335-341, 2009. 
[34] M. Kuzniarz, P. Mitchell, V. M. Flood, and J. J. Wang, "Use of vitamin and zinc supplements and age-related maculopathy: the Blue Mountains Eye Study," Ophthalmic Epidemiology, vol. 9, no. 4, pp. 283-295, 2002.

[35] J. M. Seddon, J. Cote, W. F. Page, S. H. Aggen, and M. C. Neale, "The US twin study of age-related macular degeneration: relative roles of genetic and environmental influences," Archives of Ophthalmology, vol. 123, no. 3, pp. 321-327, 2005.

[36] C. J. Hammond, A. R. Webster, H. Snieder, A. C. Bird, C. E. Gilbert, and T. D. Spector, "Genetic influence on early agerelated maculopathy: a twin study," Ophthalmology, vol. 109, no. 4, pp. 730-736, 2002.

[37] H. P. N. Scholl, M. Fleckenstein, P. C. Issa, C. Keilhauer, F. G. Holz, and B. H. F. Weber, "An update on the genetics of agerelated macular degeneration," Molecular Vision, vol. 13, pp. 196-205, 2007.

[38] C. C. W. Klaver, J. J. M. Assink, R. Van Leeuwen et al., "Incidence and progression rates of age-related maculopathy: the Rotterdam Study," Investigative Ophthalmology and Visual Science, vol. 42, no. 10, pp. 2237-2241, 2001.

[39] A. Swaroop, K. E. H. Branham, W. Chen, and G. Abecasis, "Genetic susceptibility to age-related macular degeneration: a paradigm for dissecting complex disease traits," Human Molecular Genetics, vol. 16, no. 2, pp. 174-182, 2007.

[40] R. J. Klein, C. Zeiss, E. Y. Chew et al., "Complement factor H polymorphism in age-related macular degeneration," Science, vol. 308, no. 5720, pp. 385-389, 2005.

[41] A. O. Edwards, R. Ritter III, K. J. Abel, A. Manning, C. Panhuysen, and L. A. Farrer, "Complement factor $\mathrm{H}$ polymorphism and age-related macular degeneration," Science, vol. 308, no. 5720, pp. 421-424, 2005.

[42] J. L. Haines, M. A. Hauser, S. Schmidt et al., "Complement factor $\mathrm{H}$ variant increases the risk of age-related macular degeneration," Science, vol. 308, no. 5720, pp. 419-421, 2005.

[43] S. Zareparsi, K. E. H. Branham, M. Li et al., "Strong association of the $\mathrm{Y} 402 \mathrm{H}$ variant in complement factor $\mathrm{H}$ at lq32 with susceptibility to age-related macular degeneration," The American Journal of Human Genetics, vol. 77, no. 1, pp. 149-153, 2005.

[44] J. Jakobsdottir, Y. P. Conley, D. E. Weeks, T. S. Mah, R. E. Ferrell, and M. B. Gorin, "Susceptibility genes for age-related maculopathy on chromosome 10q26," The American Journal of Human Genetics, vol. 77, no. 3, pp. 389-407, 2005.

[45] A. Rivera, S. A. Fisher, L. G. Fritsche et al., "Hypothetical LOC387715 is a second major susceptibility gene for age-related macular degeneration, contributing independently of complement factor H to disease risk," Human Molecular Genetics, vol. 14, no. 21, pp. 3227-3236, 2005.

[46] S. Schmidt, M. A. Hauser, W. K. Scott et al., "Cigarette smoking strongly modifies the association of LOC387715 and agerelated macular degeneration," The American Journal of Human Genetics, vol. 78, no. 5, pp. 852-864, 2006.

[47] L. G. Fritsche, T. Loenhardt, A. Janssen et al., "Age-related macular degeneration is associated with an unstable ARMS2 (LOC387715) mRNA," Nature Genetics, vol. 40, no. 7, pp. 892896, 2008.

[48] L. G. Fritsche, W. Chen, M. Schu et al., "Seven new loci associated with age-related macular degeneration," Nature Genetics, vol. 45, no. 4, pp. 433-439, 2013.

[49] S. M. Whitcup, A. Sodhi, J. P. Atkinson et al., "The role of the immune response in age-related macular degeneration," International Journal of Inflammation, vol. 2013, Article ID 348092, 10 pages, 2013.
[50] J. Ambati, J. P. Atkinson, and B. D. Gelfand, "Immunology of age-related macular degeneration," Nature Reviews Immunology, vol. 13, no. 6, pp. 438-451, 2013.

[51] E. Ozaki, M. Campbell, A. S. Kiang et al., "Inflammation in age-related macular degeneration," Advances in Experimental Medicine and Biology, vol. 801, pp. 229-235, 2014.

[52] J. V. Forrester, "Bowman lecture on the role of inflammation in degenerative disease of the eye," Eye, vol. 27, no. 3, pp. 340-352, 2013.

[53] W. Ansar and S. Ghosh, "C-reactive protein and the biology of disease," Immunologic Research, vol. 56, no. 1, pp. 131-142, 2013.

[54] A. Virdis, U. Dell'Agnello, and S. Taddei, "Impact of inflammation on vascular disease in hypertension," Maturitas, vol. 78, no. 3, pp. 179-183, 2014.

[55] G. Novelli, P. Borgiani, E. Giardina et al., "Role of genetics in prevention of coronary atherosclerosis," Current Opinion in Cardiology, vol. 18, no. 5, pp. 368-371, 2003.

[56] E. Giardina, C. Sinibaldi, and G. Novelli, "The psoriasis genetics as a model of complex disease," Current Drug Targets: Inflammation and Allergy, vol. 3, no. 2, pp. 129-136, 2004.

[57] G. B. Maru, K. Gandhi, A. Ramchandani, and G. Kumar, "The role of inflammation in skin cancer," Advances in Experimental Medicine and Biology, vol. 816, pp. 437-469, 2014.

[58] M. Bonomi, A. Patsias, M. Posner, and A. Sikora, "The role of inflammation in head and neck cancer," Advances in Experimental Medicine and Biology, vol. 816, pp. 107-127, 2014.

[59] P. Libby, "Inflammatory mechanisms: the molecular basis of inflammation and disease," Nutrition Reviews, vol. 65, no. 3, pp. S140-S146, 2007.

[60] G. K. Hansson, P. Libby, U. Schönbeck, and Z.-Q. Yan, "Innate and adaptive immunity in the pathogenesis of atherosclerosis," Circulation Research, vol. 91, no. 4, pp. 281-291, 2002.

[61] M. D. Turner, B. Nedjai, T. Hurst, and D. J. Pennington, "Cytokines and chemokines: at the crossroads of cell signalling and inflammatory disease," Biochimica et Biophysica ActaMolecular Cell Research, vol. 1843, no. 11, pp. 2563-2582, 2014.

[62] C. A. Janeway Jr. and R. Medzhitov, "Innate immune recognition," Annual Review of Immunology, vol. 20, pp. 197-216, 2002.

[63] R. Medzhitov and C. Janeway Jr., "Innate immunity," The New England Journal of Medicine, vol. 343, no. 5, pp. 338-344, 2000.

[64] M. Lamkanfi and V. M. Dixit, "Mechanisms and functions of inflammasomes," Cell, vol. 157, no. 5, pp. 1013-1022, 2014.

[65] P. Libby, "Inflammation and cardiovascular disease mechanisms," The American Journal of Clinical Nutrition, vol. 83, no. 2, pp. 456S-460S, 2006.

[66] D. Nuzzo, P. Picone, L. Caruana et al., "Inflammatory mediators as biomarkers in brain disorders," Inflammation, vol. 37, no. 3, pp. 639-648, 2014.

[67] M. T. Wong-Riley, "Energy metabolism of the visual system," Journal of Eye and Brain, vol. 2, pp. 99-116, 2010.

[68] M. Chen, J. V. Forrester, and H. Xu, "Dysregulation in retinal para-inflammation and age-related retinal degeneration in CCL2 or CCR2 deficient mice," PLoS ONE, vol. 6, no. 8, Article ID e22818, 2011.

[69] D. Harman, "About "origin and evolution of the free radical theory of aging: a brief personal history, 1954-2009'”' Biogerontology, vol. 10, no. 6, p. 783, 2009.

[70] S. Bank, P. S. Andersen, J. Burisch et al., "Polymorphisms in the inflammatory pathway genes TLR2, TLR4, TLR9, LY96, NFKBIA, NFKB1, TNFA, TNFRSF1A, IL6R, IL10, IL23R, PTPN22, 
and $P P A R G$ are associated with susceptibility of inflammatory bowel disease in a danish cohort," PLOS ONE, vol. 9, no. 6, Article ID e98815, 2014.

[71] S. Adami, A. Cavani, F. Rossi, and G. Girolomoni, "The role of interleukin-17A in psoriatic disease," BioDrugs, 2014.

[72] J. M. Seddon, S. George, B. Rosner, and N. Rifai, "Progression of age-related macular degeneration: prospective assessment of C-reactive protein, interleukin 6, and other cardiovascular biomarkers," Archives of Ophthalmology, vol. 123, no. 6, pp. 774782, 2005.

[73] S. V. Goverdhan, S. Ennis, S. R. Hannan et al., "Interleukin-8 promoter polymorphism -251A/T is a risk factor for age-related macular degeneration," British Journal of Ophthalmology, vol. 92, no. 4, pp. 537-540, 2008.

[74] Y.-Y. Tsai, J.-M. Lin, L. Wan et al., "Interleukin gene polymorphisms in age-related macular degeneration," Investigative Ophthalmology and Visual Science, vol. 49, no. 2, pp. 693-698, 2008.

[75] C. Garlanda, C. A. Dinarello, and A. Mantovani, "The interleukin-1 family: back to the future," Immunity, vol. 39, no. 6, pp. 1003-1018, 2013.

[76] D. Fishman, G. Faulds, R. Jeffey et al., "The effect of novel polymorphisms in the interleukin-6 (IL-6) gene on IL-6 transcription and plasma IL-6 levels, and an association with systemic-onset juvenile chronic arthritis," The Journal of Clinical Investigation, vol. 102, no. 7, pp. 1369-1376, 1998.

[77] W. E. Holmes, J. Lee, W.-J. Kuang, G. C. Rice, and W. I. Wood, "Structure and functional expression of a human interleukin-8 receptor," Science, vol. 253, no. 5025, pp. 1278-1280, 1991.

[78] P. M. Murphy and H. L. Tiffany, "Cloning of complementary DNA encoding a functional human interleukin-8 receptor," Science, vol. 253, no. 5025, pp. 1280-1283, 1991.

[79] L.-B. Gao, X.-M. Pan, J. Jia et al., "IL-8 -251A/T polymorphism is associated with decreased cancer risk among population-based studies: Evidence from a meta-analysis," European Journal of Cancer, vol. 46, no. 8, pp. 1333-1343, 2010.

[80] Y.-Y. Tsai, J.-M. Lin, L. Wan et al., "Interleukin gene polymorphisms in age-related macular degeneration," Investigative Ophthalmology \& Visual Science, vol. 49, no. 2, pp. 693-698, 2008.

[81] A. Simonini, M. Moscucci, D. W. M. Muller et al., "IL-8 is an angiogenic factor in human coronary atherectomy tissue," Circulation, vol. 101, no. 13, pp. 1519-1526, 2000.

[82] F. Ricci, G. Staurenghi, T. Lepre et al., "Haplotypes in IL-8 gene are associated to age-related macular degeneration: a casecontrol study," PLoS ONE, vol. 8, no. 6, Article ID e66978, 2013.

[83] S. Mélik-Parsadaniantz and W. Rostène, "Chemokines and neuromodulation," Journal of Neuroimmunology, vol. 198, no. 12, pp. 62-68, 2008.

[84] R. Colobran, E. Pedrosa, L. Carretero-Iglesia, and M. Juan, "Copy number variation in chemokine superfamily: the complex scene of CCL $3 L-C C L 4 L$ genes in health and disease," Clinical \& Experimental Immunology, vol. 162, no. 1, pp. 41-52, 2010.

[85] N. K. Sharma, A. Gupta, S. Prabhakar, R. Singh, A. K. Bhatt, and A. Anand, "CC chemokine receptor-3 as new target for agerelated macular degeneration," Gene, vol. 523, no. 1, pp. 106-111, 2013.

[86] A. Takeda, J. Z. Baffi, M. E. Kleinman et al., "CCR3 is a target for age-related macular degeneration diagnosis and therapy," Nature, vol. 460, no. 7252, pp. 225-230, 2009.
[87] F. Parmeggiani, F. S. Sorrentino, M. R. Romano et al., "Mechanism of inflammation in age-related macular degeneration: an up-to-date on genetic landmarks," Mediators of Inflammation, vol. 2013, Article ID 435607, 13 pages, 2013.

[88] L. A. Trouw and M. R. Daha, "Role of complement in innate immunity and host defense," Immunology Letters, vol. 138, no. 1, pp. 35-37, 2011.

[89] R. Klein, C. E. Myers, K. J. Cruickshanks et al., "Markers of inflammation, oxidative stress, and endothelial dysfunction and the 20-year cumulative incidence of early age-related macular degeneration the beaver dam eye study," JAMA Ophthalmology, vol. 132, no. 4, pp. 446-455, 2014.

[90] E. C. Schramm, S. J. Clark, M. P. Triebwasser et al., "Genetic variants in the complement system predisposing to age-related macular degeneration: a review," Molecular Immunology, vol. 5890, no. 14, pp. 161-163, 2014.

[91] A. MacHalińska, M. P. Kawa, W. Marlicz, and B. MacHaliński, "Complement system activation and endothelial dysfunction in patients with age-related macular degeneration (AMD): possible relationship between AMD and atherosclerosis," Acta Ophthalmologica, vol. 90, no. 8, pp. 695-703, 2012.

[92] S. J. Clark, P. N. Bishop, and A. J. Day, "Complement factor H and age-related macular degeneration: the role of glycosaminoglycan recognition in disease pathology," Biochemical Society Transactions, vol. 38, no. 5, pp. 1342-1348, 2010.

[93] L. A. Donoso, T. Vrabec, and H. Kuivaniemi, “The role of complement factor $\mathrm{H}$ in age-related macular degeneration: a review," Survey of Ophthalmology, vol. 55, no. 3, pp. 227-246, 2010.

[94] D. D. G. Despriet, C. C. W. Klaver, J. C. M. Witteman et al., "Complement factor $\mathrm{H}$ polymorphism, complement activators, and risk of age-related macular degeneration," The Journal of the American Medical Association, vol. 296, no. 3, pp. 301-309, 2006.

[95] F. Ricci, S. Zampatti, F. D’Abbruzzi et al., “Typing of ARMS2 and $\mathrm{CFH}$ in age-related macular degeneration: case-control study and assessment of frequency in the Italian population," Archives of Ophthalmology, vol. 127, no. 10, pp. 1368-1372, 2009.

[96] J. M. Seddon, Y. Yu, E. C. Miller et al., "Rare variants in CFI, C3 and C9 are associated with high risk of advanced age-related macular degeneration," Nature Genetics, vol. 45, no. 11, pp. 13661373, 2013.

[97] A. Thakkinstian, M. McEvoy, U. Chakravarthy et al., "The association between complement component 2/complement factor B polymorphisms and age-related macular degeneration: a HuGE review and meta-analysis," American Journal of Epidemiology, vol. 176, no. 5, pp. 361-372, 2012.

[98] C. Sun, M. Zhao, and X. Li, “CFB/C2 gene polymorphisms and risk of age-related macular degeneration: a systematic review and meta-analysis," Current Eye Research, vol. 37, no. 4, pp. 259271, 2012.

[99] J. M. Seddon, R. Reynolds, J. Maller, J. A. Fagerness, M. J. Daly, and B. Rosner, "Prediction model for prevalence and incidence of advanced age-related macular degeneration based on genetic, demographic, and environmental variables," Investigative Ophthalmology and Visual Science, vol. 50, no. 5, pp. 2044-2053, 2009.

[100] M. M. Markiewski and J. D. Lambris, “The role of complement in inflammatory diseases from behind the scenes into the spotlight," American Journal of Pathology, vol. 171, no. 3, pp. 715727, 2007. 
[101] G. Wang, K. L. Spencer, W. K. Scott et al., "Analysis of the indel at the ARMS2 $3^{\prime}$ UTR in age-related macular degeneration," Human Genetics, vol. 127, no. 5, pp. 595-602, 2010.

[102] A. Kanda, W. Chen, M. Othman et al., "A variant of mitochondrial protein LOC387715/ARMS2, not HTRA1, is strongly associated with age-related macular degeneration," Proceedings of the National Academy of Sciences of the United States of America, vol. 104, no. 41, pp. 16227-16232, 2007.

[103] G. Wang, K. L. Spencer, B. L. Court et al., "Localization of agerelated macular degeneration-associated ARMS2 in cytosol, not mitochondria," Investigative Ophthalmology and Visual Science, vol. 50, no. 7, pp. 3084-3090, 2009.

[104] G. Wang, K. L. Spencer, W. K. Scott et al., "Analysis of the indel at the ARMS2 $3^{\prime}$ UTR in age-related macular degeneration," Human Genetics, vol. 127, no. 5, pp. 595-602, 2010.

[105] T. R. Yasuma, M. Nakamura, K. M. Nishiguchi et al., "Elevated c-reactive protein levels and ARMS2/HTRA1 gene variants in subjects without age-related macular degeneration," Molecular Vision, vol. 16, pp. 2923-2930, 2010.

[106] J. M. Seddon, G. Gensler, and B. Rosner, "C-reactive protein and CFH, ARMS2/HTRA1 gene variants are independently associated with risk of macular degeneration," Ophthalmology, vol. 117, no. 8, pp. 1560-1566, 2010

[107] F. Zeng, M. Zhang, Y. Xu, and H. Xu, "ARMS2 interference leads to decrease of proinflammatory mediators," Graefe's Archive for Clinical and Experimental Ophthalmology, vol. 251, no. 11, pp. 2539-2544, 2013.

[108] M. Campbell and S. L. Doyle, "An eye on the future of inflammasomes and drug development in AMD," Journal of Molecular Medicine, vol. 91, no. 9, pp. 1059-1070, 2013.

[109] J. K. Dowling and L. A. J. O’Neill, "Biochemical regulation of the inflammasome," Critical Reviews in Biochemistry and Molecular Biology, vol. 47, no. 5, pp. 424-443, 2012.

[110] S. L. Masters and L. A. J. O’Neill, “Disease-associated amyloid and misfolded protein aggregates activate the inflammasome," Trends in Molecular Medicine, vol. 17, no. 5, pp. 276-282, 2011.

[111] K. Schroder, R. Zhou, and J. Tschopp, “The NLRP3 inflammasome: a sensor for metabolic danger?” Science, vol. 327, no. 5963, pp. 296-300, 2010.

[112] A. Kauppinen, H. Niskanen, T. Suuronen, K. Kinnunen, A. Salminen, and K. Kaarniranta, "Oxidative stress activates NLRP3 inflammasomes in ARPE-19 cells-implications for agerelated macular degeneration (AMD)," Immunology Letters, vol. 147, no. 1-2, pp. 29-33, 2012.

[113] O. A. Anderson, A. Finkelstein, and D. T. Shima, "A2E induces IL-1 $\beta$ production in retinal pigment epithelial cells via the NLRP3 inflammasome," PLoS ONE, vol. 8, no. 6, Article ID e67263, 2013.

[114] R. T. Liu, J. Gao, S. Cao et al., "Inflammatory mediators induced by amyloid-beta in the retina and RPE in vivo: implications for inflammasome activation in age-related macular degeneration," Investigative Ophthalmology and Visual Science, vol. 54, no. 3, pp. 2225-2237, 2013.

[115] W. A. Tseng, T. Thein, K. Kinnunen et al., "NLRP3 inflammasome activation in retinal pigment epithelial cells by lysosomal destabilization: implications for age-related macular degeneration," Investigative Ophthalmology and Visual Science, vol. 54, no. 1, pp. 110-120, 2013.

[116] R. Ehrlich, A. Harris, N. S. Kheradiya, D. M. Winston, T. A. Ciulla, and B. Wirostko, "Age-related macular degeneration and the aging eye," Clinical Interventions in Aging, vol. 3, no. 3, pp. 473-482, 2008.
[117] L. Hyman and R. Neborsky, "Risk factors for age-related macular degeneration: an update," Current Opinion in Ophthalmology, vol. 13, no. 3, pp. 171-175, 2002. 


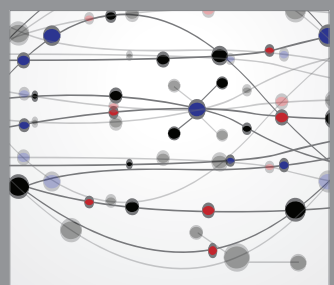

The Scientific World Journal
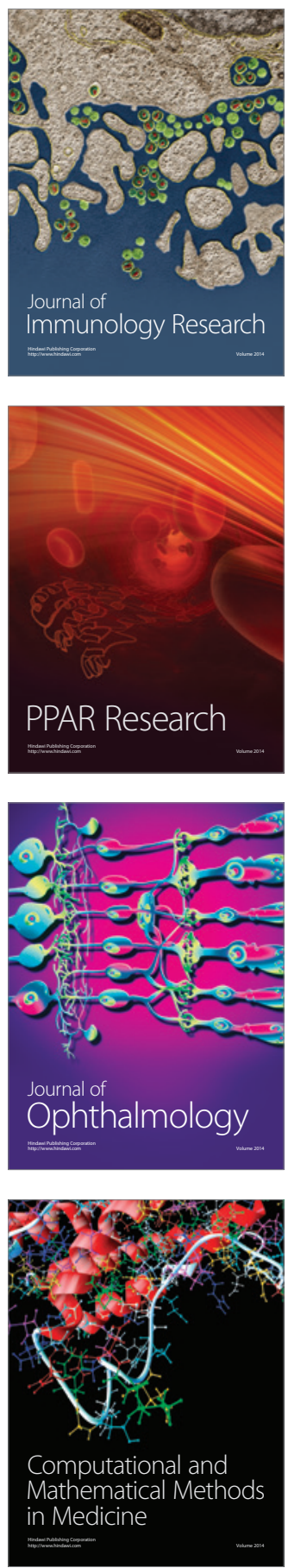

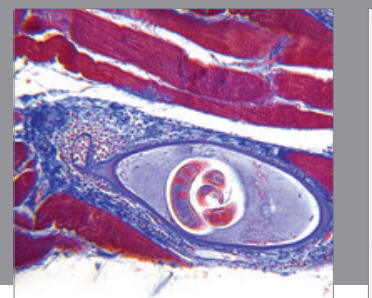

Gastroenterology

Research and Practice
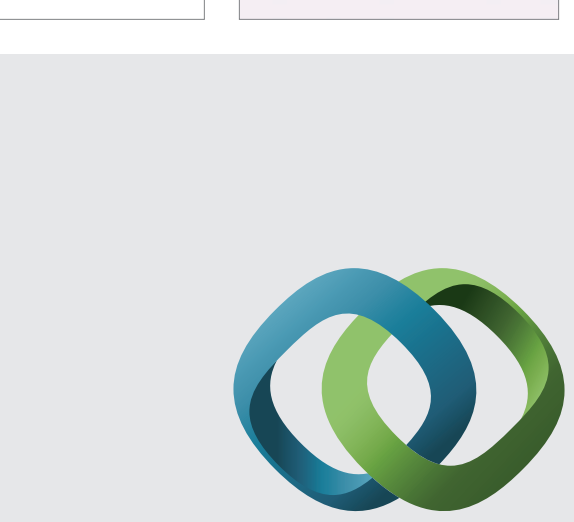

\section{Hindawi}

Submit your manuscripts at

http://www.hindawi.com
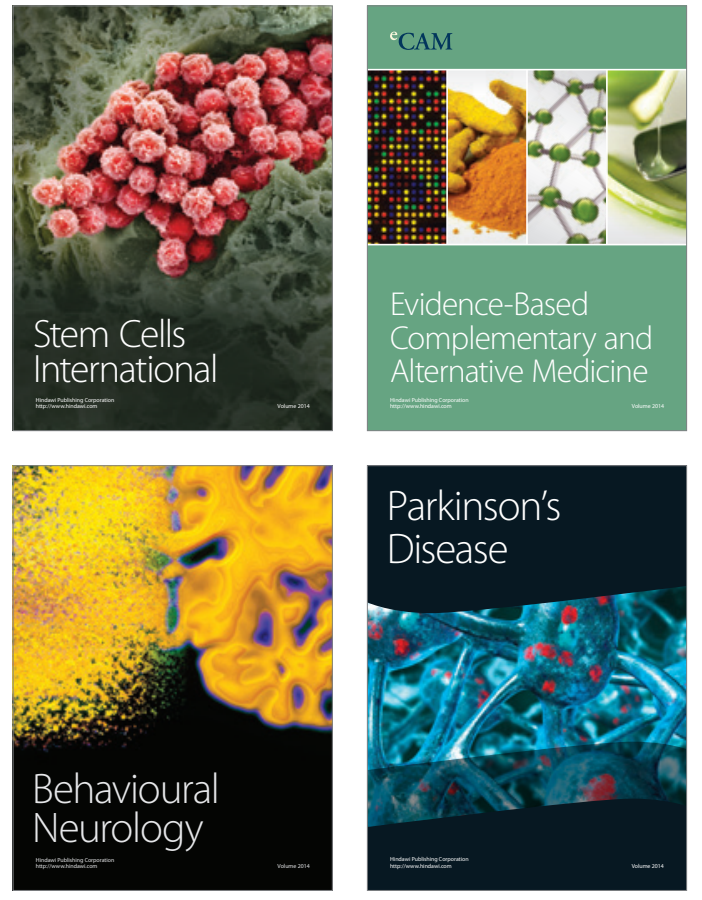
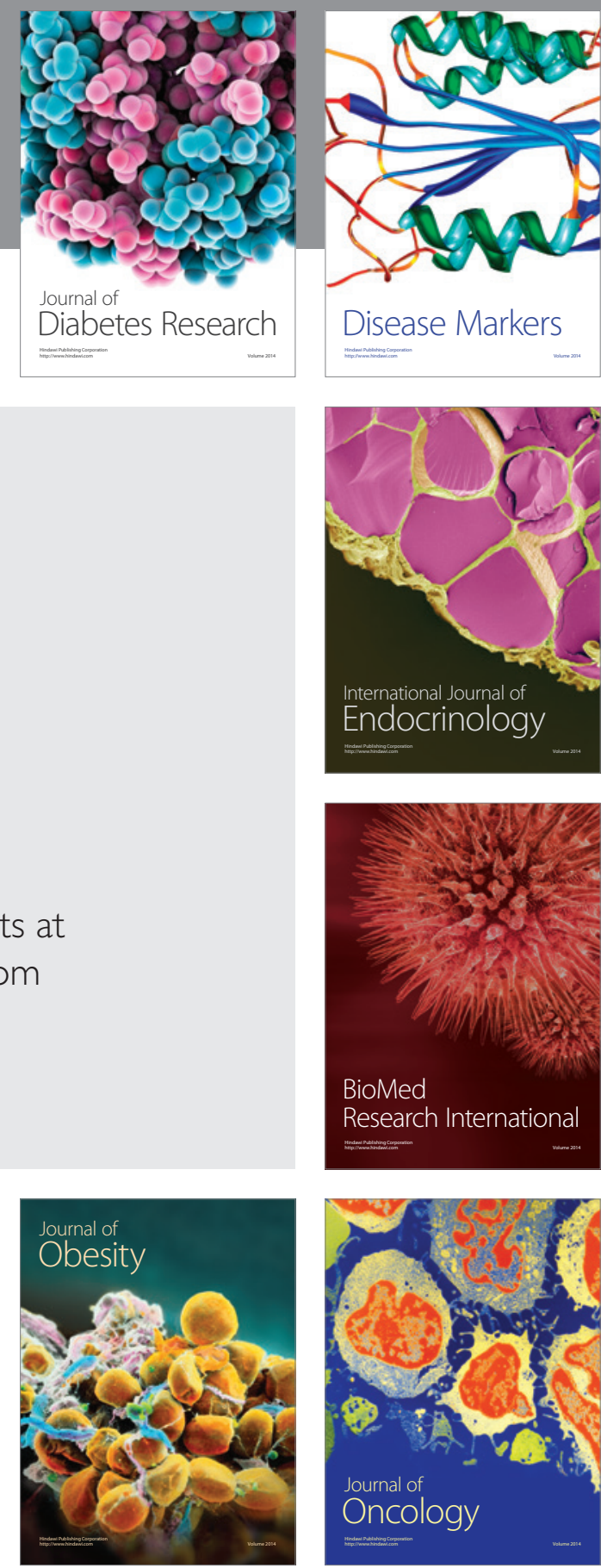

Disease Markers
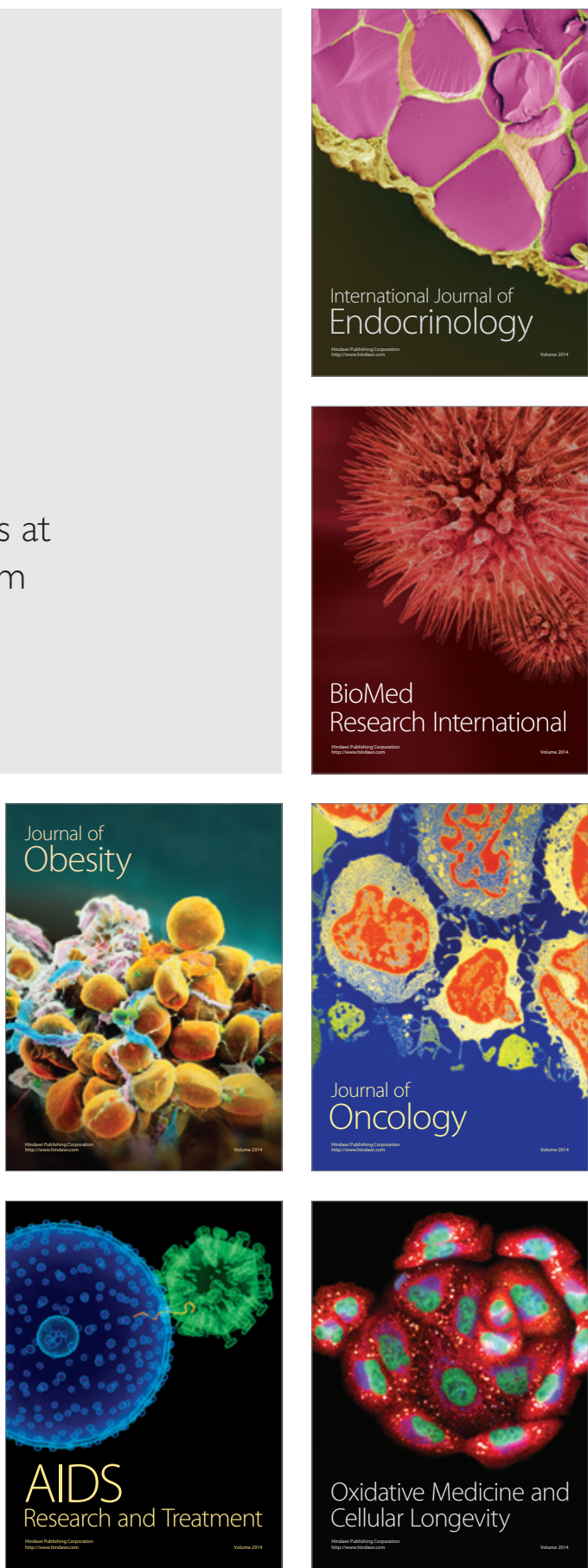